Pontifícia Universidade Ce Católica

Emmy Uehara Pires

\title{
Ontogênese das Funções Cognitivas: Uma Abordagem Neuropsicológica
}

\author{
Dissertação de Mestrado
}

Dissertação apresentada como requisito parcial para obtenção do grau de Mestre pelo Programa de Pós-graduação em Psicologia Clínica do Departamento de Psicologia do Centro de Teologia e Ciências Humanas da PUC-Rio.

Orientador: Prof. Jesus Landeira-Fernandez

Rio de Janeiro

Fevereiro de 2010 
Pontifícia U Universidade Ce Católica

Emmy Uehara Pires

\section{Ontogênese das Funções Cognitivas: Uma Abordagem Neuropsicológica}

Dissertação apresentada como requisito parcial para obtenção do grau de Mestre pelo Programa de Pós-Graduação em Psicologia Clínica do Departamento de Psicologia do Centro de Teologia e Ciências Humanas da PUC-Rio. Aprovada pela Comissão Examinadora abaixo assinada.

Prof. Jesus Landeira Fernandez Orientador

Departamento de Psicologia - PUC-Rio

Prof ${ }^{a}$. Helenice Charchart-Fichmann

Departamento de Psicologia - PUC-Rio

Profe. Rosinda Martins Oliveira

Departamento de Psicologia - UFRJ

Prof. Paulo Fernando Carneiro de Andrade Coordenador Setorial de Pós-Graduação

e Pesquisa do Centro de Teologia e Ciências Humanas - PUC-Rio

Rio de Janeiro, /2010. 
Todos os direitos reservados. É proibida a reprodução total ou parcial do trabalho sem autorização do autor, do orientador e da universidade.

\section{Emmy Uehara Pires}

Graduou-se em Psicologia pela Universidade Federal do Rio de Janeiro em 2005. Possui experiência na área de Neuropsicologia, atuando principalmente no seguinte tema: desenvolvimento infantil, avaliação neuropsicológica e maturação cerebral.

Ficha Catalográfica

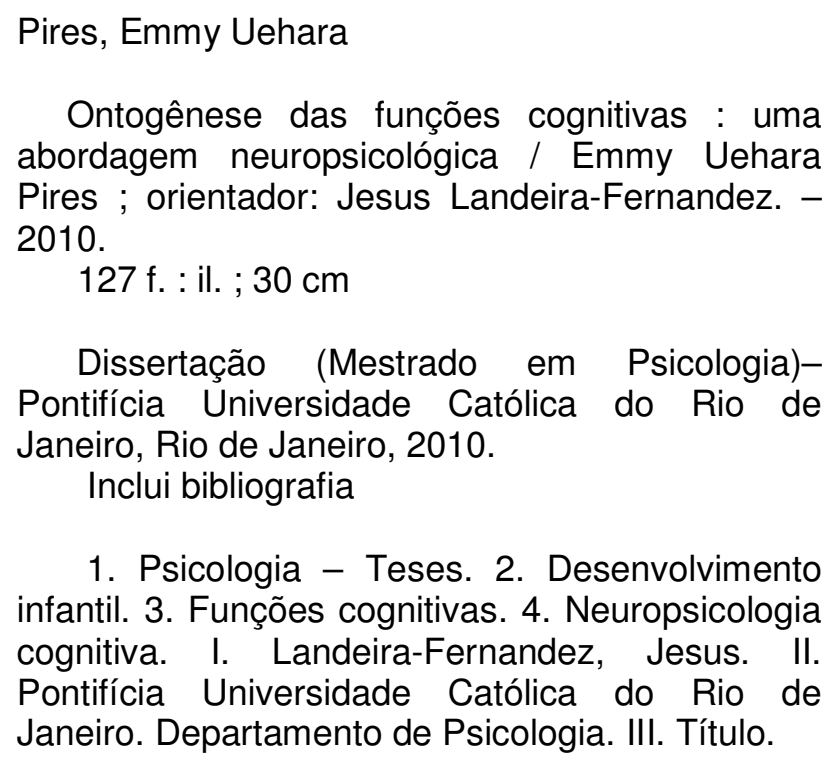

1. Psicologia - Teses. 2. Desenvolvimento infantil. 3. Funções cognitivas. 4. Neuropsicologia cognitiva. I. Landeira-Fernandez, Jesus. II. Pontifícia Universidade Católica do Rio de Janeiro. Departamento de Psicologia. III. Título.

CDD: 150 
Aos meus queridos pais, que tornaram tudo possível em minha vida e por terem feito de mim a pessoa que sou hoje. 


\section{Agradecimentos}

Manifesto meu sincero agradecimento a todas as pessoas que, de forma significativa, fizeram com que este trabalho fosse possível:

Ao meu orientador, J. Landeira, pelo exemplo acadêmico, onde a cordialidade e respeito estiveram sempre presentes.

À professora Helenice Charchat, pelos preciosos e descompromissados conselhos.

Aos professores que fazem parte desta banca examinadora, pela atenção e disponibilidade em pleno período de férias.

À PUC-Rio e à CAPES, pelos auxílios concedidos, sem os quais este trabalho não poderia ter sido realizado.

À minha querida UFRJ, pela formação profissional e pessoal.

À Secretaria Municipal de Educação da Cidade do Rio de Janeiro, aos diretores, professores e funcionários das escolas, por terem confiado em nosso trabalho e colaborado cedendo espaço e tempo de seus horários para a pesquisa.

À todas as crianças/adolescentes e responsáveis e, que consentiram a participação nesta pesquisa e contribuíram para o aprimoramento do nosso conhecimento.

À todos meus ex-pacientes e examinandos, que me ensinaram aquilo que não se encontra em livros. Muito obrigada pela lição de vida!

Aos funcionários do Departamento de Psicologia PUC-Rio, pelo constante carinho e simpatia.

Aos meus amigos da equipe, Ana Carolina Fioravanti, Bruno Larrubia, Bruno Galvão, Erica de Lana, Flávia Paes, Luciene Rocinholi, Marta Bolshaw, Renata Vianna, Tânia Netto, Vitor Castro e Yossi Zana, pelos momentos de companherismo, força e motivação durante meu mestrado.

Aos meus amigos de pesquisa, Luciana Brooking, Raphael Suwwan, Glória Marques, Gabriela Tuche e Adriano Miranda, por me ajudarem em todos os problemas enfrentados, meus ataques de pânico e sem dúvida alguma, disponibilidade de tempo.

Aos meus inseparáveis amigos da faculdade: Bárbara, Eduardo, Lívia e Mariana, pelas vidas compartilhadas, risadas, afeto e palavras doces nas horas mais difíceis.

Em especial, ao meu companheiro de vida, Fabiano, que soube em cada momento, me amar, compreender e incentivar todos meus sonhos. Simplesmente, por tudo aquilo que você significa pra mim. 


\section{Resumo}

Pires, Emmy Uehara; Landeira-Fernandez, Jesus (Orientador). Ontogênese das funções cognitivas: Uma abordagem neuropsicológica. Rio de Janeiro, 2010. 127p. Dissertação de Mestrado - Departamento de Psicologia, Pontifícia Universidade Católica do Rio de Janeiro.

O presente estudo teve como objetivo compreender como se dá a ontogênese das funções cognitivas no período entre o nascimento até o início da adolescência. A partir da perspectiva da neurociência e neuropsicologia cognitiva, questões como as influências biológicas e ambientais, a maturação cerebral e o processo de aprendizagem, assim como as bases neuroanatômicas e circuitos neurais serão discutidas. A ênfase será dada aos marcos mais relevantes no processo típico do desenvolvimento das principais funções cognitivas tais como a sensação, a percepção, a atenção, a memória, a linguagem, as habilidades visuoconstrutivas, e as funções executivas.

\section{Palavras-chave}

Desenvolvimento Infantil; funções cognitivas; neuropsicologia cognitiva. 


\section{Abstract}

Pires, Emmy Uehara; Landeira-Fernandez, Jesus (Advisor). Ontogenese of cognitive functions: A neuropsychological approach. Rio de Janeiro, 2010.127p. MSc. Dissertation - Departamento de Psicologia, Pontifícia Universidade Católica do Rio de Janeiro.

This study aimed to understand how the ontogeny of cognitive functions during the period from birth to early adolescence. From the perspective of neuroscience and cognitive neuropsychology, issues such as biological and environmental influences, brain maturation and learning processes, as neuroanatomical bases and neural circuits will be discussed. Emphasis will be given to the most important milestones in the typical development of the main cognitive functions such as sensation, perception, attention, memory, language, visual-constructive skills and executive functions.

\section{Keywords}

Child development; cognitive functions; cognitive neuropsychology. 


\section{Sumário}

1. Introdução

2. A Neuropsicologia do Ser Humano 15

2.1. Desenvolvimento Infantil 17

2.2. Maturação Cerebral e Aprendizagem 18

2.3. Funções Cognitivas 22

3. Funções Cognitivas: Bases Neuroanatômicas e Circuitarias 24

3.1. Sensação e Percepção 26

3.2. Atenção 28

3.3. Memória 29

3.4. Linguagem 32

3.5. Habilidades Visuo-Construtivas 33

3.6. Funções Executivas 34

4. Funções Cognitivas: Ontogênese/Desenvolvimento 38

4.1. Sensação e Percepção 39

4.1.1. Visão 40

4.1.2. Audição 41

4.1.3. Olfato, Paladar e Tato 43

4.1.4. Percepção intermodal ou multissensorial 44

4.2. Atenção $\quad 45$

4.2.1. Ativação ou Estado de Alerta 46

4.2.2. Orientação e Atenção Visual 47

4.2.3. Atenção Voluntária e Seletiva 49

4.2.4. Atenção Sustentada $\quad 50$

4.3. Memória $\quad 51$

4.3.1. Memória de Trabalho: Alça Fonológica 52

4.3.2. Memória de Trabalho: Esboço Visuo-espacial 53

4.3.3. Memória de Trabalho: Executivo Central e Retentor Episódico 54

4.3.4. Memória de Longo Prazo: Explícita ou Declarativa 55

4.3.5. Memória de Longo Prazo: Implícita ou Não-Declarativa 56

4.4. Linguagem 58

4.4.1. Fonologia-Fonética: Os Sons e a Percepção da Fala 59

4.4.2. Semântica-Léxico: As Palavras e Seus Significados 61

4.4.3. Morfossintaxe-Gramática: Combinação das Palavras 62

4.4.4. Pragmática: Os Usos Comuns da Linguagem 63

4.5. Habilidades visuo-construtivas: 64

4.5.1. Desenho Livre e da Figura Humana 65

4.5.1. Reprodução, Construção e Escrita 66 
$\begin{array}{ll}\text { 4.6. Funções Executivas } & 67\end{array}$

4.6.1. Controle Inibitório 68

4.6.2. Organização e Planejamento 69

4.6.3. Flexibilidade Cognitiva 70

4.6.4. Fluência Verbal 71

4.6.5. Teoria da Mente 72

5. Conclusão 73

5.1. Uma visão geral nas fases do desenvolvimento 75

5.2. Um olhar específico em cada função cognitiva 76

5.3. Funções executivas: Uma nova perspectiva ao pensar sobre o 78 desenvolvimento?

6. Referências Bibliográficas 81

$\begin{array}{lr}\text { Anexo } & 113\end{array}$ 


\section{Lista de Figuras e Tabelas}

Figura 1 - Período de maturação cerebral 19

Figura 2 - Períodos decisivos para desenvolvimento e aprendizado 21

Figura 3 - Esquema das vias dorsal e ventral $\quad 27$

Figura 4 - Memória de longo prazo e suas estruturas associadas 30

Tabela 1 - Áreas corticais relacionadas aos diferentes componentes da 31 memória de trabalho

Figura 5 - Circuitos do córtex pré-frontal e as funções executivas 35

Figura 6 - Desenvolvimento das principais funções da atenção visual $\quad 49$

Tabela 2 - Desenvolvimento da linguagem falada 60

Tabela 3 - Desenvolvimento lexical até os seis anos 61 


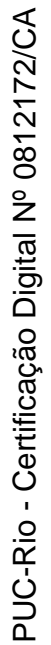

"Things do not change; we change." Henry D. Thoreu 